\title{
Performance of Two-Area Interconnected Power System with High Wind Power Penetration in Presence of Plug-in Hybrid Electric Vehicles
}

\author{
Mahmoud Essam Harby \\ Said Elsayed Elmasry \\ Adel Elsamahy
}

Faculty of Engineering- Helwan University, Cairo, Egypt

Luis Marroyo

Javier Marcos

Faculty of Engineering, Public University of Navarra (UPNA), Spain

Doi: 10.19044/esj.2018.v14n30p311 URL:http://dx.doi.org/10.19044/esj.2018.v14n30p311

\begin{abstract}
Most of existing power grids are designed neither by latest technologies nor to comply with quickly climate changes, the new intelligent power grids are urgently needed and will soon be applied to the power markets. In the smart grid, the large-scale renewable energy contribution tends to expand vastly. This paper is focusing on the wind energy. Wind's inherent intermittency and unpredictability make its increased penetration into the power system grids an area requiring significant analysis and research. Notwithstanding, because of the changeable nature of the wind energy, this may lead to a high oscillation on the power system frequency. From another aspect, A lot of scientific research is searching for smart solutions and tools to support and enhance the integration of the renewable energy resources into the electrical grids without additional costs for the power system, so the world scientific research is directed to exploit the plugin hybrid electric vehicles (PHEVs) which are considered as the sustainable and environmental friendly transportation system in the next period around the world. PHEVs are considered as the scattered batteries, which will enhance the integrating of the renewable energy resources into the electrical power system. In this paper, the performance of two-area interconnected power system with high wind energy penetration is analyzed in the presence of the plug-in hybrid electric vehicles when using Ziegler and Nicholas method (Nguyen \& Mitra, 2018).
\end{abstract}


Keywords: Large wind penetration, Wind integration, Plug-in hybrid electric vehicles, Power system frequency oscillation, Smart storage systems

\section{Introduction}

Millions of people suffer from the effects of the climate change around the world and there are many rising worries around the world about the energy independence and the global warming issues. In order to get rid of further risks of the climate change, the world countries need to reduce their $\mathrm{CO} 2$ emission with at least 80-95 percent before the year 2050. Climate scientists agree on this fact. In order to achieve this, 80-90 percent of our energy must be produced through the renewable resources by 2050 according to Wind Energy Solutions (WES), Spanbroek. The expansion of renewable energy technologies and resources, especially wind and solar sources, continues to face many hindrances in spite of the spectacular cost reduction in the last decade, some of these hindrances are legal, technical concerns, but many of these hindrances are based on inefficiencies-limitations associated with communications, structures, and proceedings that have adapted in a centralized, fossil fuel-centric power market according to Synapse Energy Economics (SEE). This research is focusing on the technical hindrances that the expansion of the wind energy faces nowadays. The fact of that the Wind blows when it chooses, which is often not when it is needed most, so due to this changeable nature of the wind speed, the power system stability and reliability are affected. This problem could be resolved by using an adequate electrical storage system, but from another vision, the additional storage systems will require an additional cost, wide space, infrastructure and continuous maintenance. All these points will not make the investors to be enthusiastic to invest their money in this field (Richardson, 2013).

From another aspect, plug-in electric vehicles - including electric-only plug-in electric vehicles and plug-in hybrid electric vehicles (PHEVs) are going to become much more common in upcoming years. Nowadays, there are three basic types of electrical vehicles. The first type is the purely electric vehicle $(\mathrm{EV})$, meaning that it runs solely on a battery powered motor, which is plugged into the electrical grid either at home if you have one installed, or at a public charging points. There is no internal combustion engine installed on board the vehicle, but this means that there is no backup power supply for it when the electric charge begins to drain. Over the past couple of years, the race to produce an EV with an extended range has been on top of the agenda with the big players in the electric car world. The second type is the hybrid electric vehicle (HEV), it uses two propulsion methods to power the car. Combining an internal combustion engine and an electric motor, the vehicle utilizes the electric motor during low-speed travel and switches to the internal 
combustion engine when more power is needed. If the vehicle needs an added boost, then both propulsion methods work simultaneously. The main power source of the HEV is the gasoline powered internal combustion engine; however, the HEV generates its electricity through its regenerative braking system, which stores the electricity on board (Zhang \& Mi, 2011).

The third type is the plug-in hybrid electric vehicle (PHEV), it takes its power from both an electric motor and an internal combustion engine. However, a PHEV uses the electric motor as the main power source, and uses the internal combustion engine as a generator, which kicks in when the battery reaches a predetermined state of charge (SOC). The main difference between the HEV and the PHEV is the way in which the vehicle is electrically powered. The HEV creates its own electricity through regenerative braking systems, while a PHEV a plugged directly into the electric grid and can be used for longer distances. From the previous comparison, it's clear that the PHEVs are the best solution for the world future transportation system from the practical point of view and the environmental point of view, so the PHEVs is the used type of electric vehicles in this paper. PHEVs will be the smartest solution to be used as a smart storage system, which will enhance the integration of the renewable energy resources such as solar and wind resources into the smart grids.

This paper provides an overview about one the most possible enhancing solution for integrating the wind energy into the power system grids. Therefore, in this paper, the performance of two area interconnected power system with high wind energy penetration is investigated in the presence and absence of the plug-in hybrid electric vehicles and a fruitful comparison is provided to clarify the significant role of the PHEVs in smoothing the power system frequency, maintaining the power system reliability and stability and mitigating the negative effects of the extra penetration of the wind energy resources into the power system. This paper is divided as follows, the second section provides a two-area interconnected power system without using the PHEVs and the third section discusses a twoarea interconnected power system when using the PHEVs on each area, then in the fourth section, a fruitful comparison is held between both case studies to illustrate the effective role of the PHEVs in smoothing the power system frequency and enhancing the integration of the wind energy into the power system (Vachirasricirikul \& Ngamroo, 2014).

\section{Performance of two-area interconnected power system without using PHEVs:}

A two-area interconnected power system with large wind farms is considered for the simulation study as shown in Fig. 1. With the studied system, each area consists of the wind farm, the thermal power plant, and the 
variable load. Fig. 2 presents the MATLAB model of the proposed system. The wind farm of both areas consists of thirty-two wind turbines, each turbine has a rated power of three MWs. The maximum load on the system for area one is two hundred-fifty Megawatt, and two hundred-ten Megawatts for area two (Mi \& Masrur, 2017).

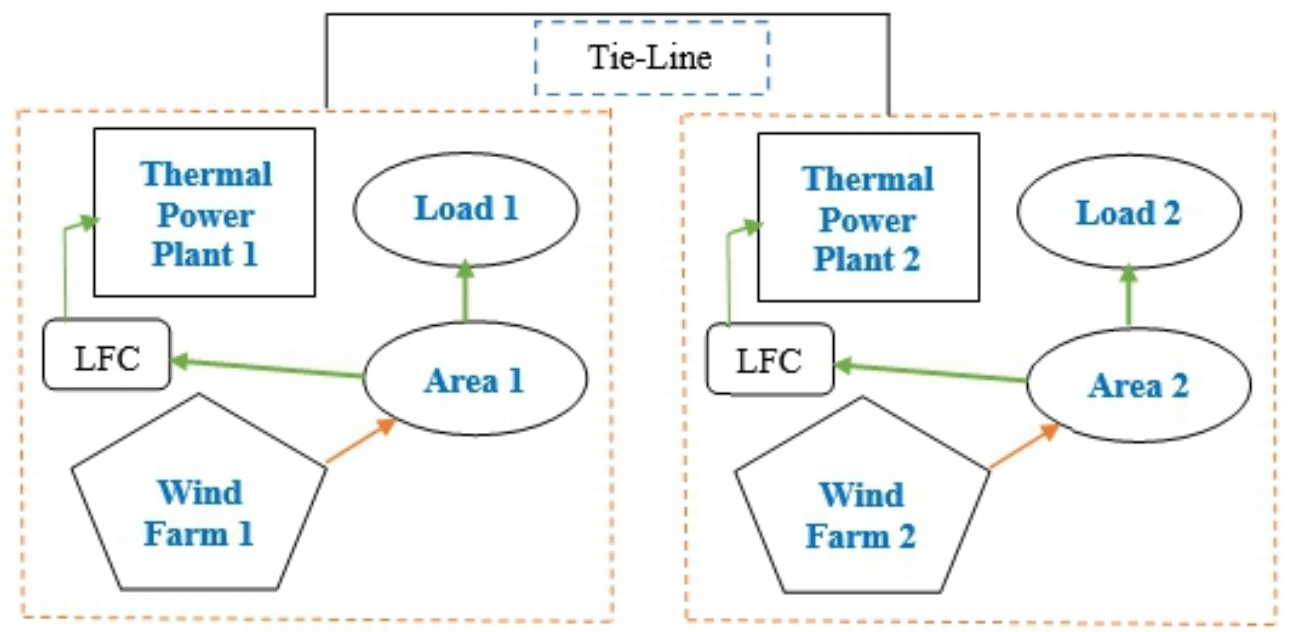

Figure 1: General layout of the desired system.

\section{Without PHEVs}
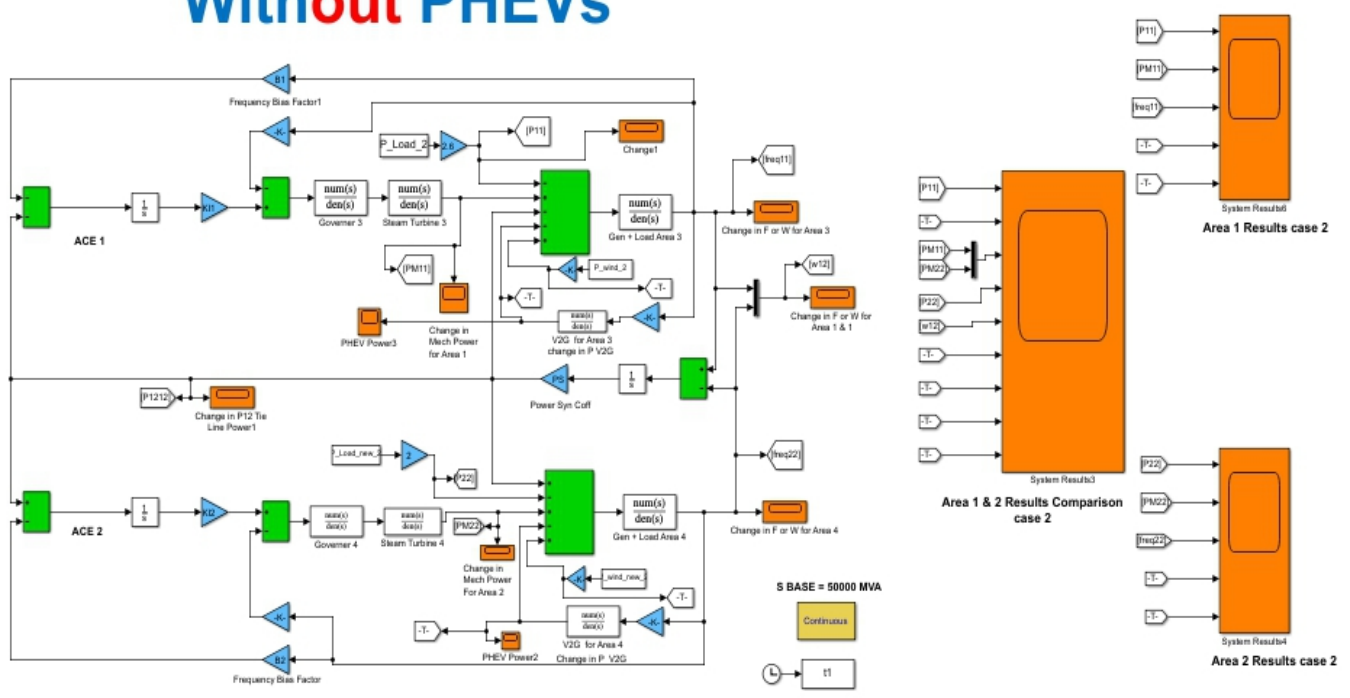

Figure 2: MATLAB model of the proposed power system for the first case.

In this section, the different responses of the two areas are described, each area variable load, the power delivered by the thermal power plant, the power delivered by the wind farm and the power system frequency. Fig. 3 illustrates the results for area one and Fig. 4 presents the results for area two. Fig. 5 shows the tie-line power between both areas. 


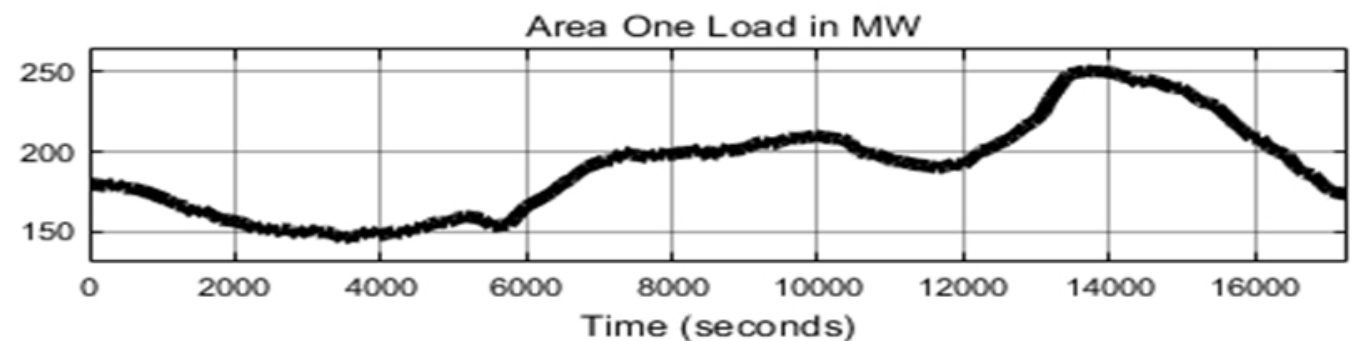

Area One Thermal Plant Power in MW

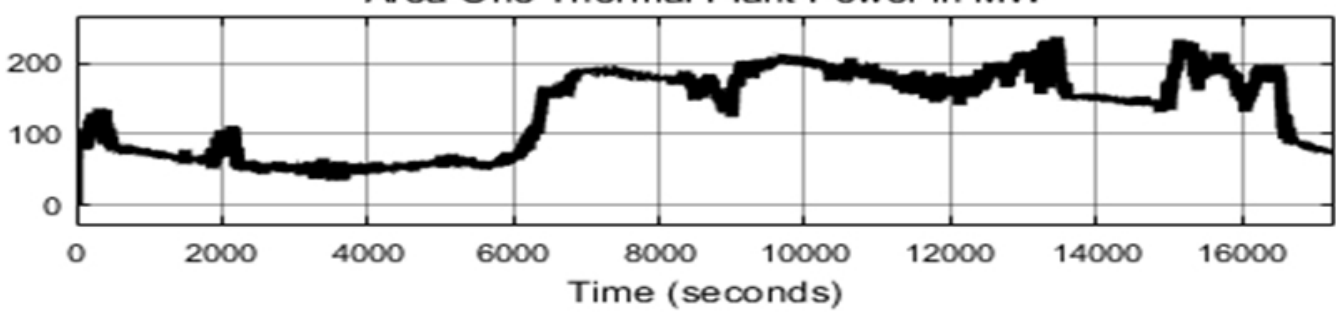

Area One Frequency in P.U
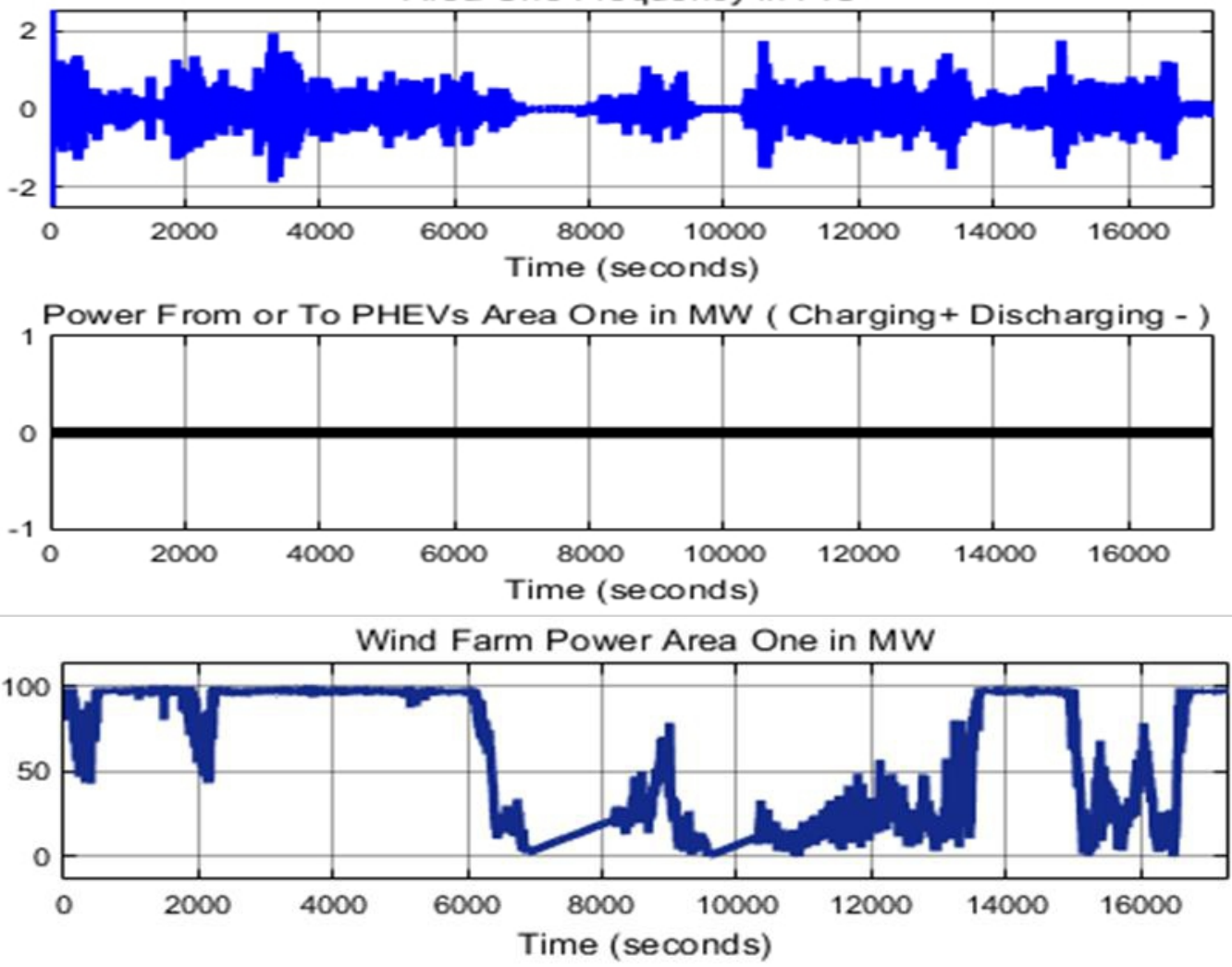

Figure 3: The different results and responses for area one. 

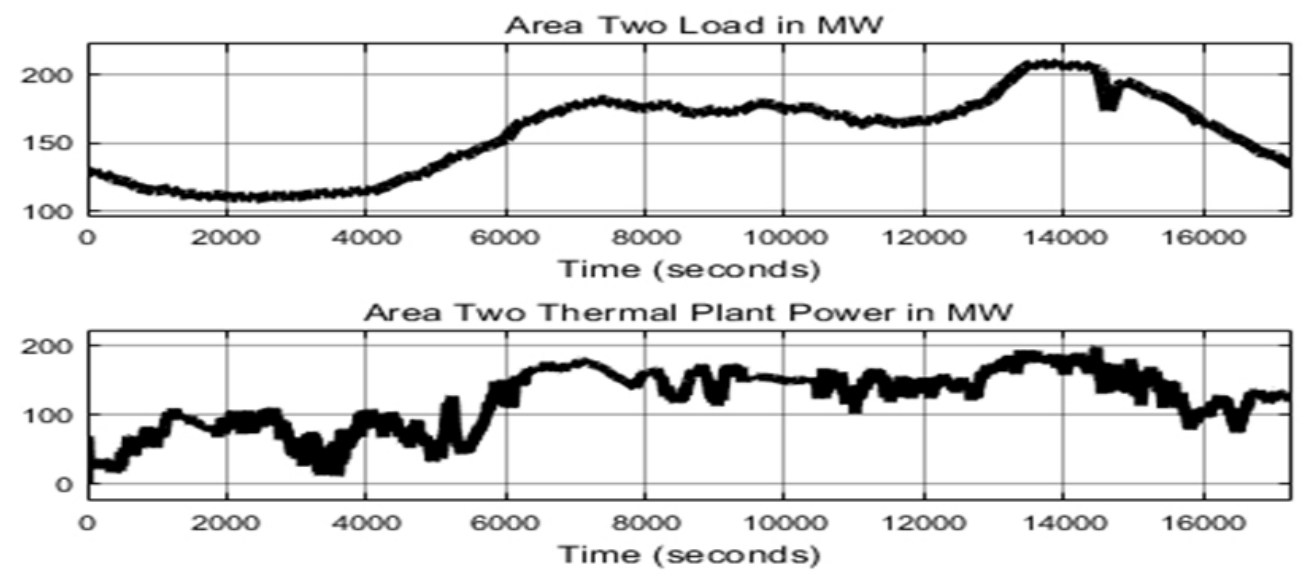

Area Two Frequency in P.U
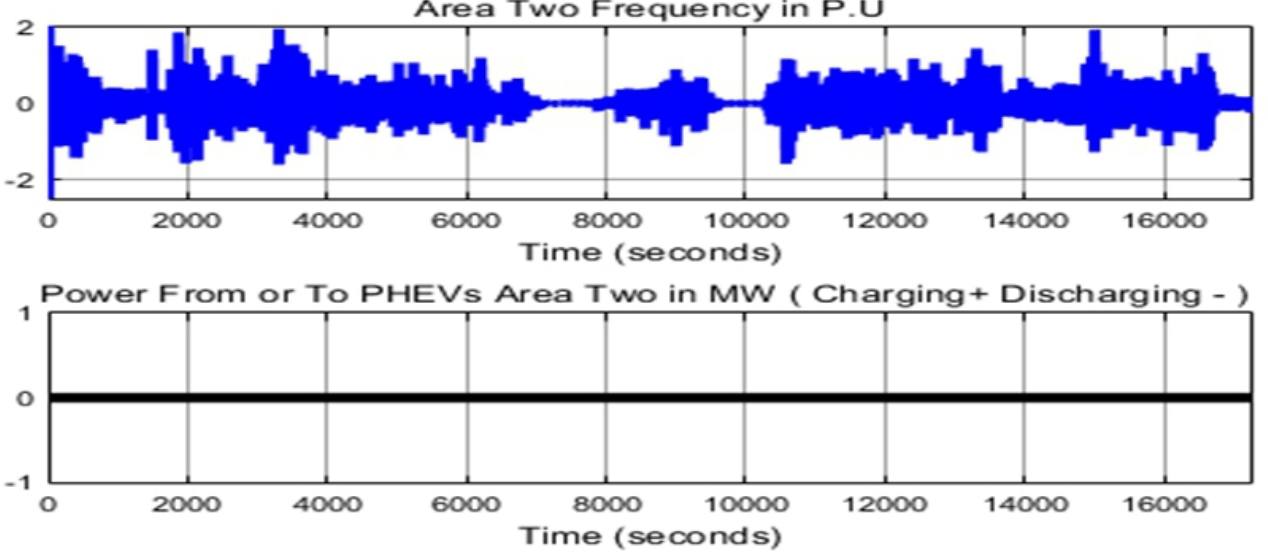

Wind Farm Power Area Two in MW

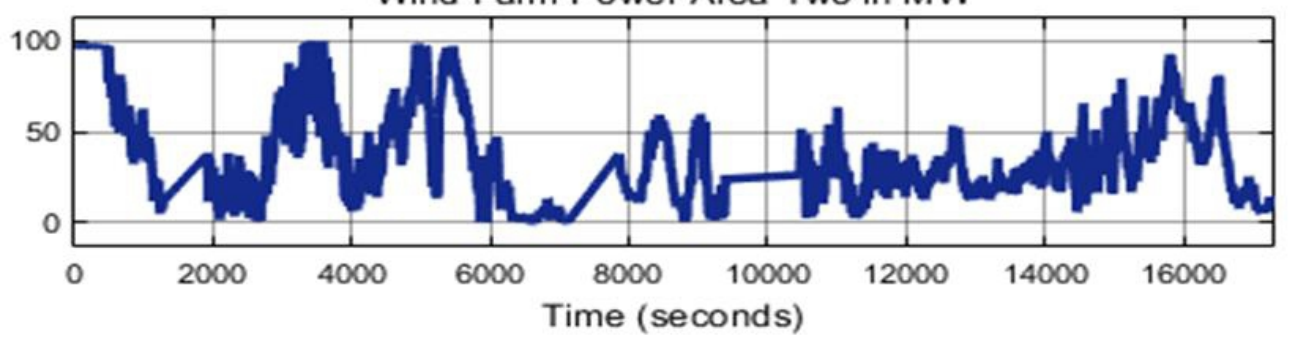

Figure 4: The different results and responses for area two.

Tie Line Power in MW

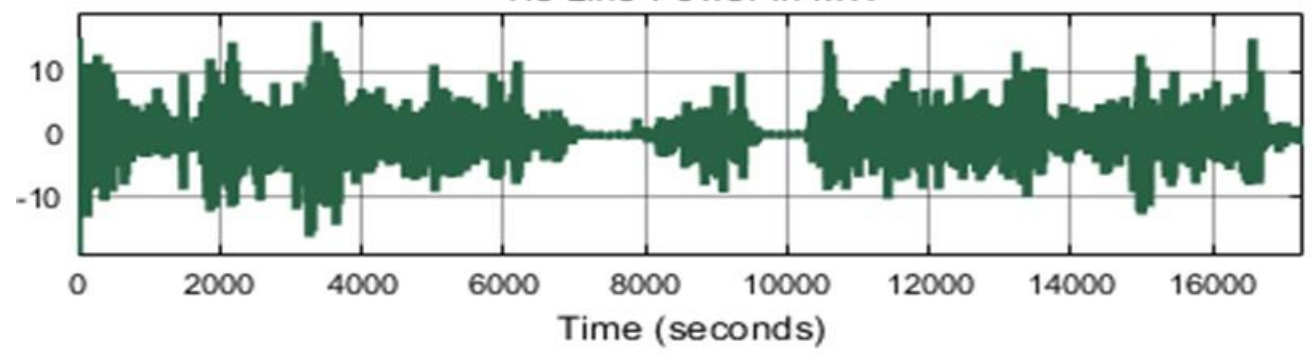

Figure 5: Tie-line power between both areas. 
From the different results and responses of both areas, it's obvious that due to the presence of the high wind power penetration in both areas, there is a lot of oscillation in the power system frequency, this oscillation increases as the contribution of the wind energy increases into the power system, this is because of the intermittent nature of the wind speed as discussed in the introduction.

\section{Performance of two-area interconnected power system when using PHEVs:}

In the next case study an investigation of the performance of two-area interconnected power system with high wind power penetration in the presence of plug-in hybrid electric vehicles is provided to clarify the significant role of the PHEVs in smoothing the power system frequency and mitigating the negative effects of the extra penetration of the wind energy into the power system. A simple model of the PHEVs vehicle to grid mode $(\mathrm{V} 2 \mathrm{G})$ is clarified in Fig. 6 and the proposed system layout for the second case study is described in Fig. 7.

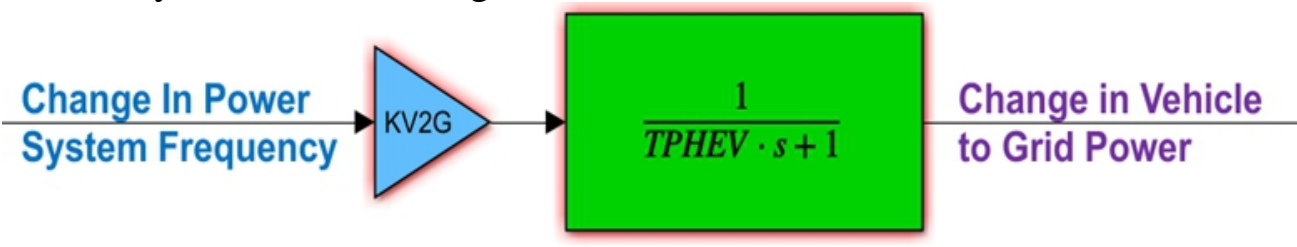

Figure 6: Model of the PHEVs vehicle to grid mode (V2G).

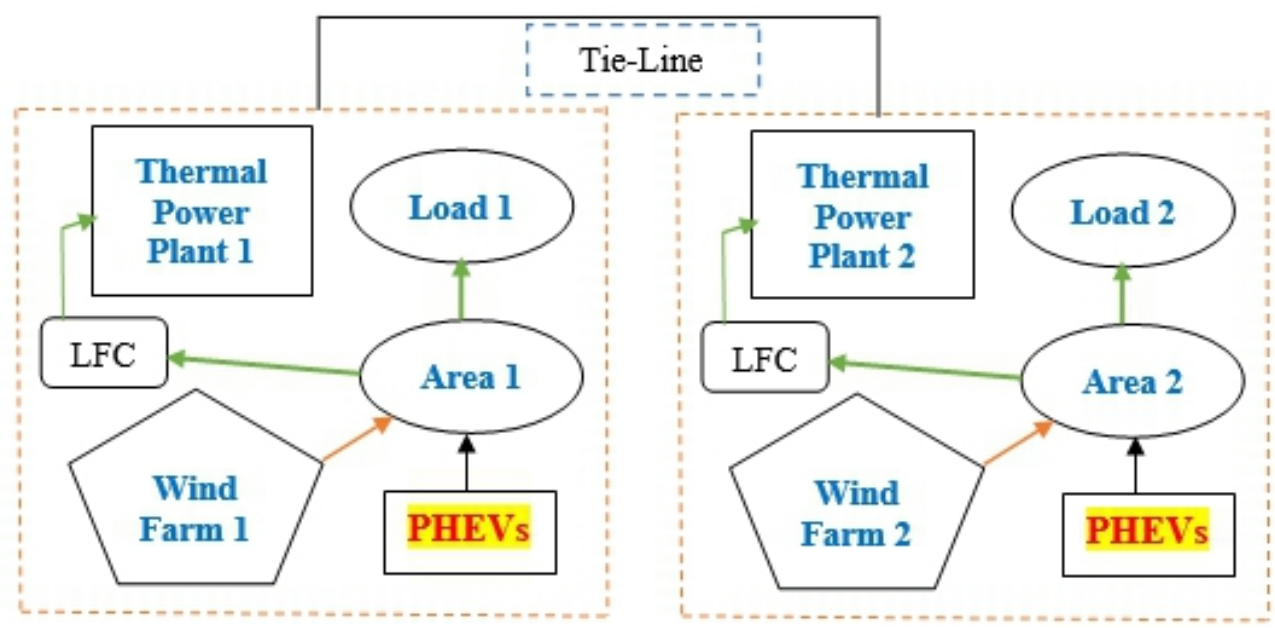

Figure 7: General layout of the desired system.

In this section, the different results of the two areas are provided, each area variable load, the plug- in hybrid electric vehicle power, the power supplied by the thermal power plant, the power generated by the wind farm 
and the power system frequency. Fig. 8 presents the results for area one and Fig. 9 shows the results for area two. Fig. 10 illustrates the tie-line power between both areas.
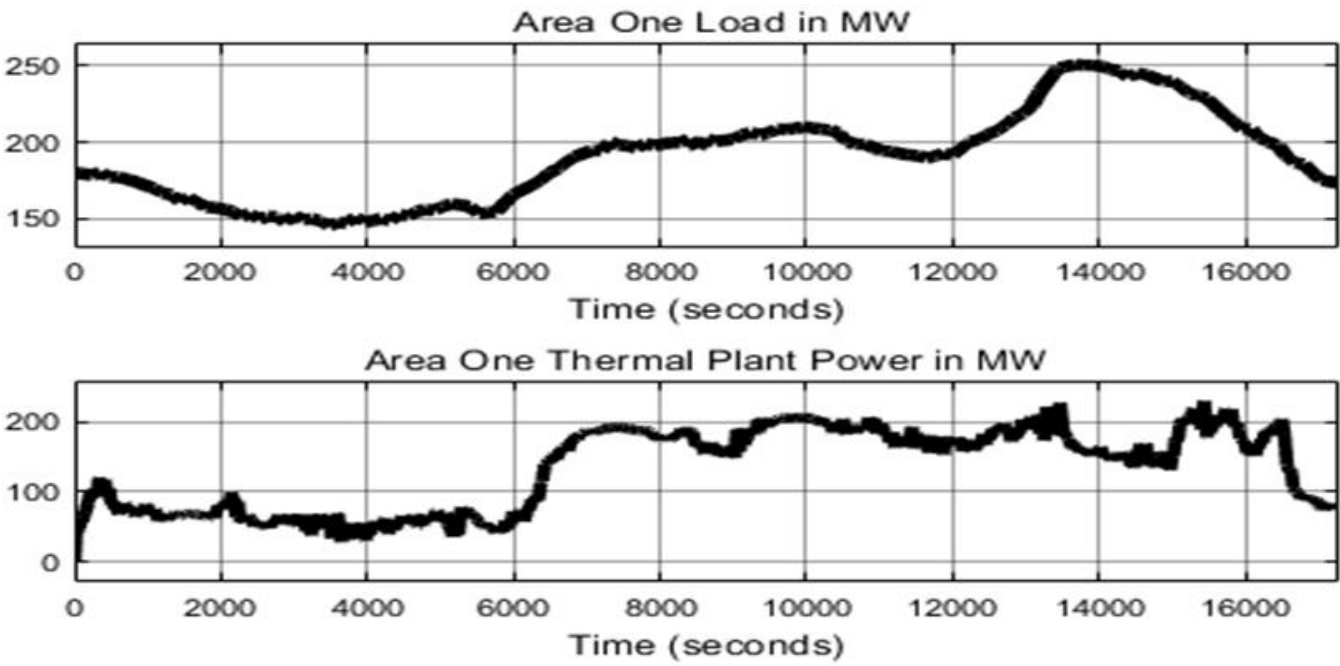

Area One Frequency in P.U

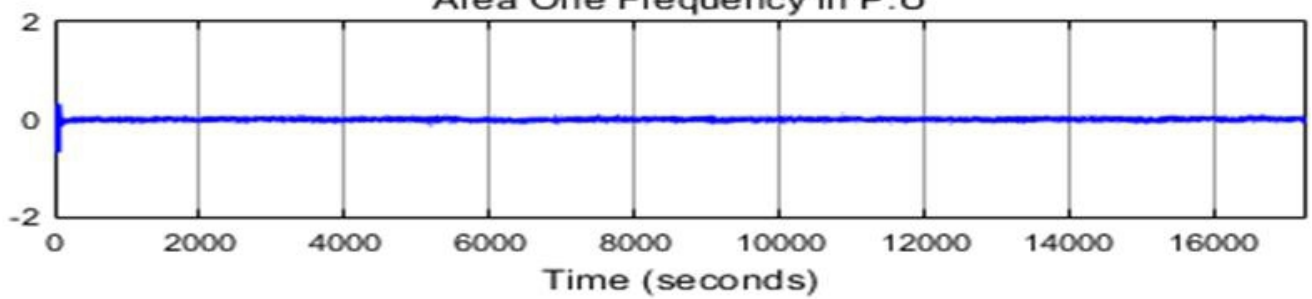

Power From or To PHEVs Area One in MW ( Charging + Discharging - )
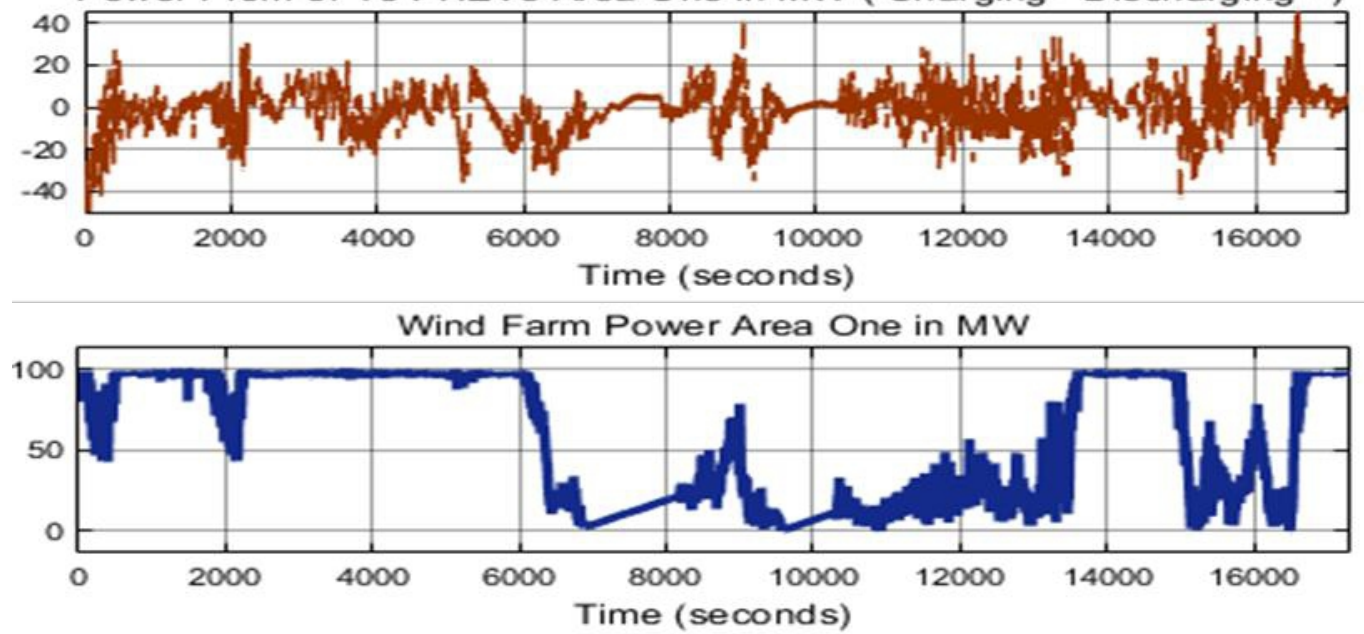

Figure 8: The different results and responses for area one. 


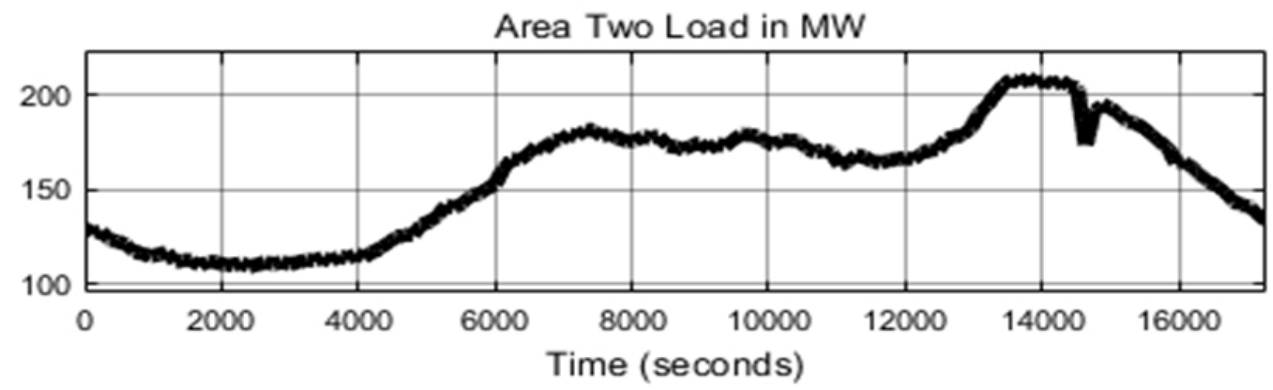

Area Two Thermal Plant Power in MW

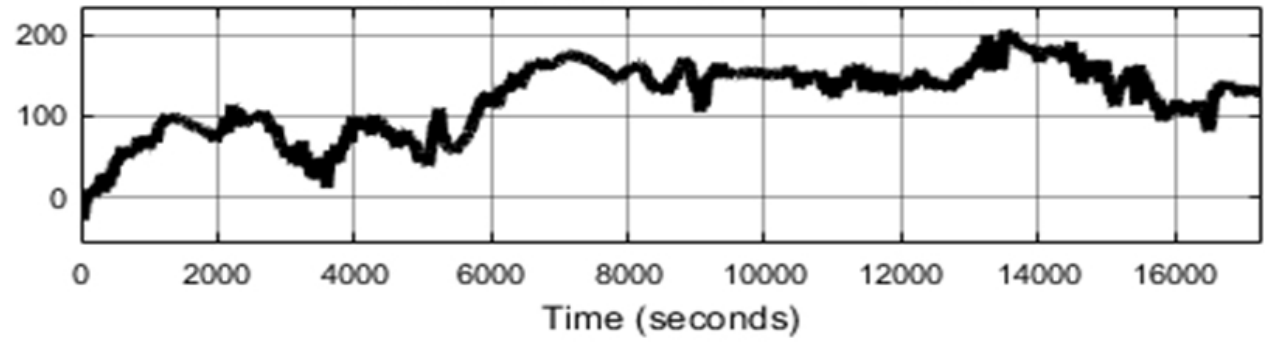

Area Two Frequency in P.U

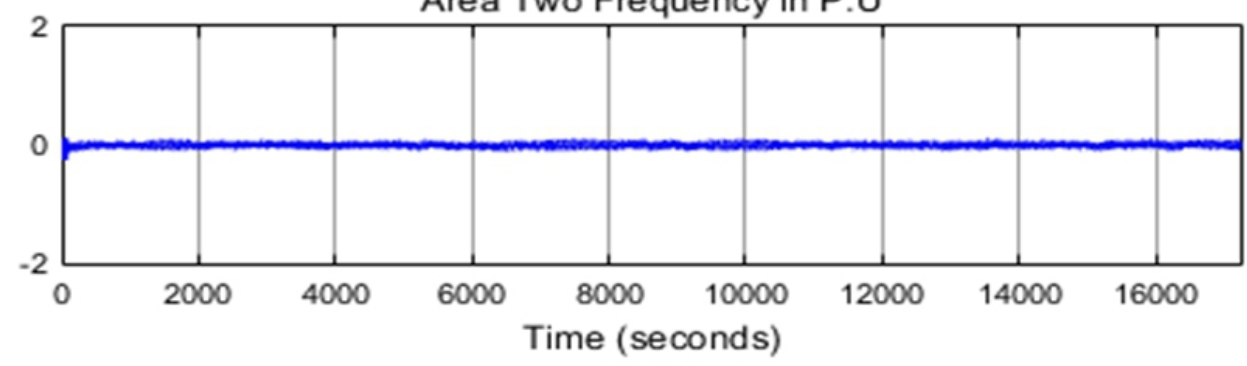

Power From or To PHEVs Area Two in MW ( Charging + Discharging - )

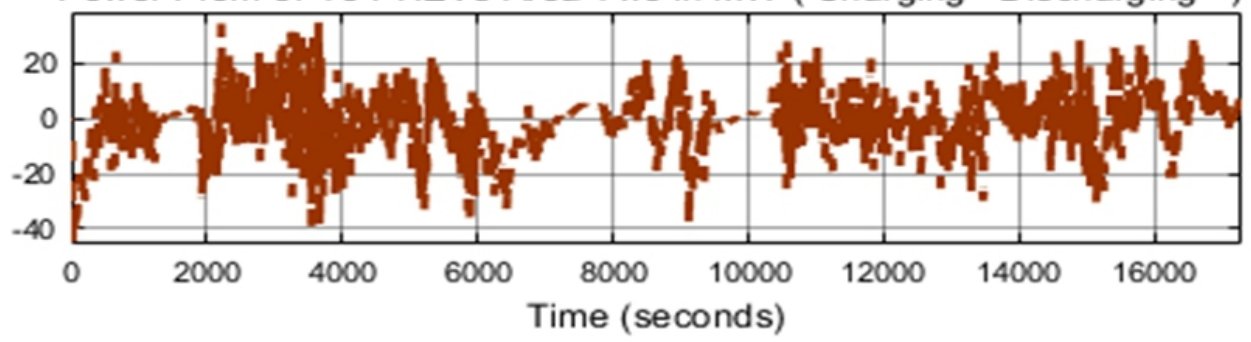

Wind Farm Power Area Two in MW

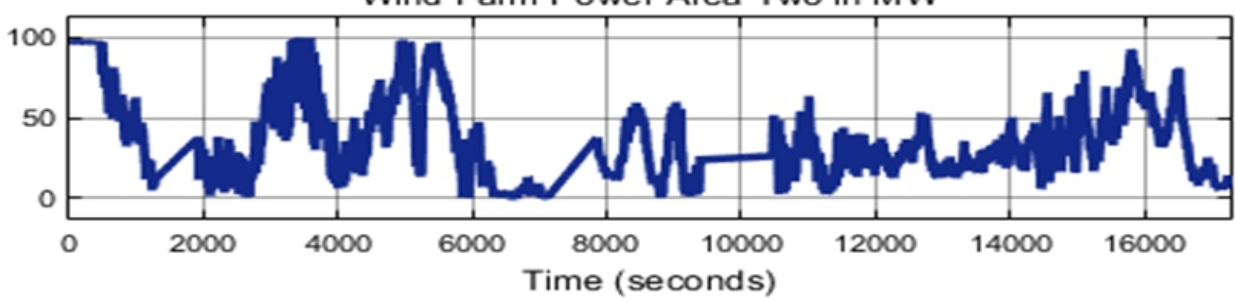

Figure 9: The different results and responses for area two. 
Tie Line Power in MW

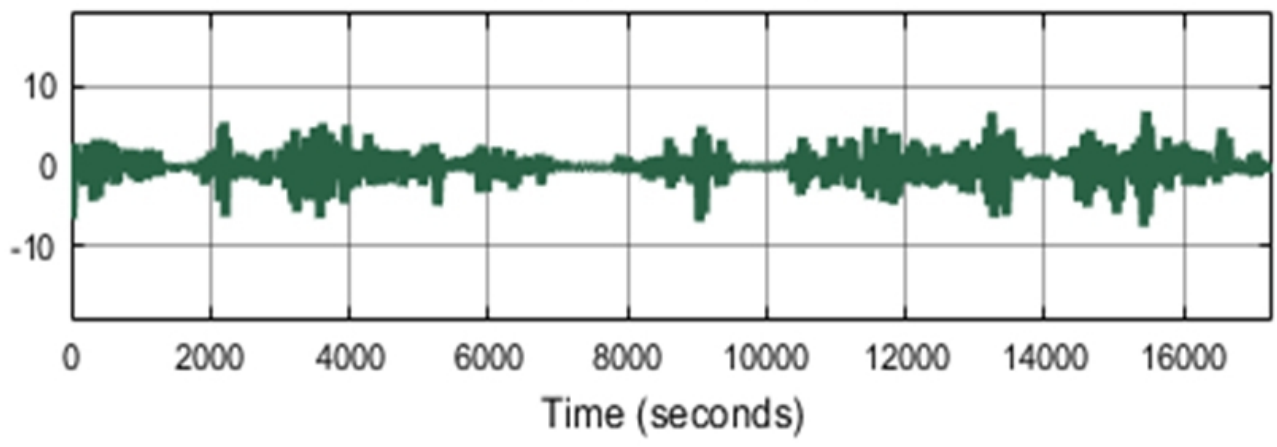

Figure 10: The tie-line power.

As presented in the results, the plug-in hybrid electric vehicles (PHEVs) can play a very effective and significant role in smoothing the power system frequency during the wind fluctuations. PHEVs present a lot of potentials in supporting power grids with large contribution of wind energy, since they can act as a very fast response generator source in vehicle to grid (Discharging mode to inject power back to the grid when necessary) and vice versa, since they can act as a demand or load in grid to vehicle (Charging mode), so PHEVs can be considered as one of the most suitable solutions for integrating the renewable energy sources into the electrical grids and maintaining the power system stability and reliability without additional cost (Kabouris \& Kanellos, 2009).

\section{Comparison between both case studies:}

After studying each case study alone, an enhanced comparison is presented in this section to show how effective is the PHEVs in smoothing the power system frequency during the wind speed fluctuations. Fig. 11 illustrates the power in the tie-line in both cases. Fig. 12 presents the frequency of both areas in the presence and absence of the PHEVs.

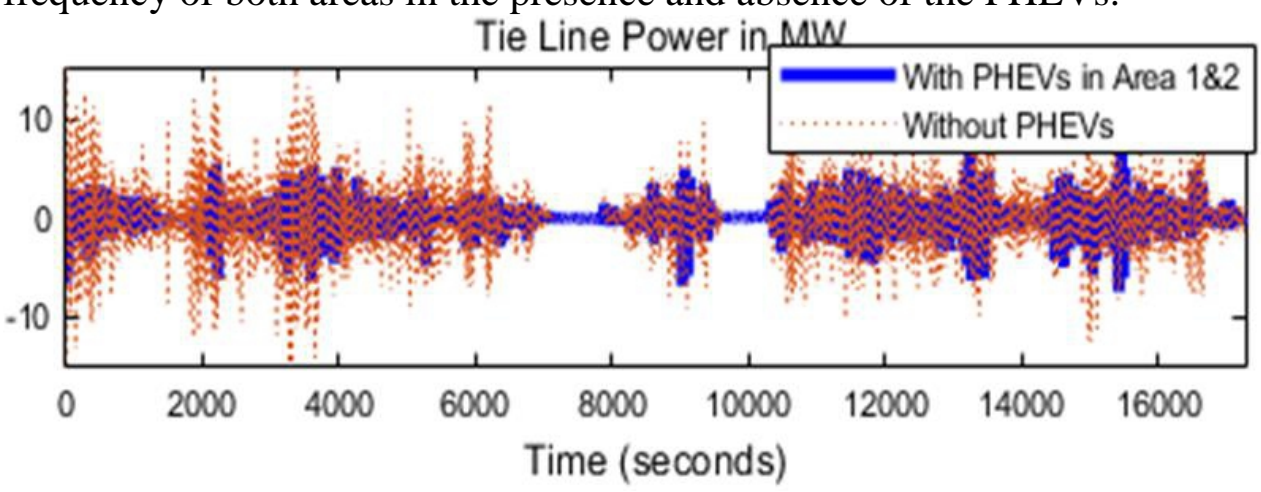

Figure 11: Tie-line power in MW for both cases. 

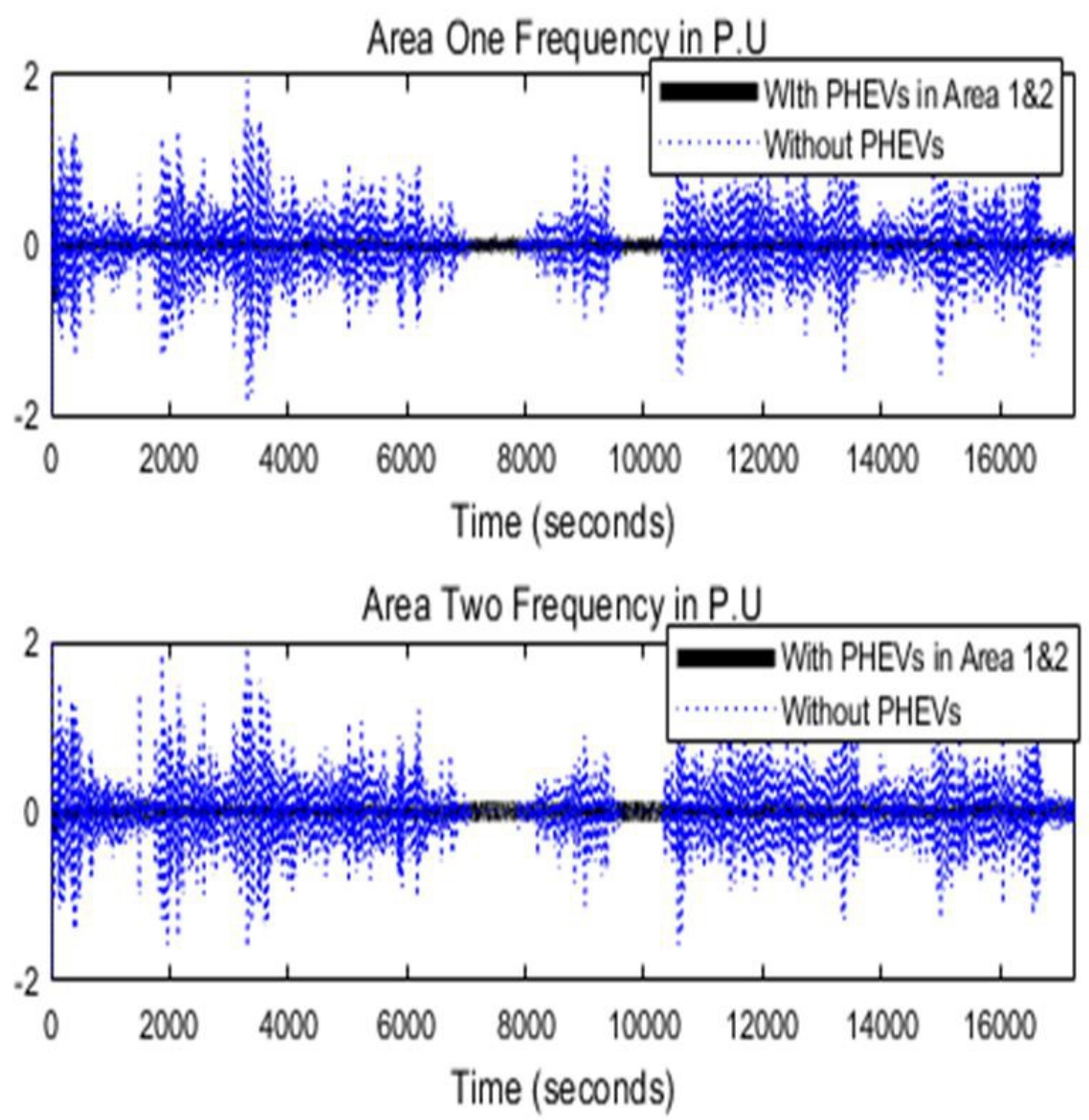

Figure 12: Comparison between the frequency responses of both cases.

\section{Conclusion}

In this paper, the performance of two-area interconnected power system with high wind energy penetration is investigated in the presence and absence of the plug-in hybrid electric vehicles when using Ziegler and Nicholas method to select the optimal values of the controller parameters. An enhancing comparison is provided to clarify the significant role of the PHEVs in smoothing the power system frequency, maintaining the power system reliability and stability. The results show that the plug-in hybrid electric vehicles can play a very effective and significant role in integrating the renewable energy resources, especially the wind resources into the smart grids without additional cost. The simulation results demonstrate the ability of the proposed system to achieve the objective function and satisfy the various constraints under different case studies (Extra wind and less wind).

The designed controller was very effective, where the parameters of the controller have been selected by Ziegler and Nicholas method which is 
very simple and fast method to get the suitable values of the controller gains. As far as future work is concerned, although power loss is not yet considered in this stage, it will be considered with the view to further enhancement of the system's efficiency. Moreover, future work will explore the possibilities of using a hierarchial framework to coordinate the centralised control centre with a decentralised controller in each individual vehicle.

\section{References:}

1. Nguyen, N. and Mitra, J., 2018. Reliability of power system with high wind penetration under frequency stability constraint. IEEE Transactions on Power Systems, 33(1), pp.985-994.

2. Richardson, D.B., 2013. Electric vehicles and the electric grid: A review of modeling approaches, Impacts, and renewable energy integration. Renewable and Sustainable Energy Reviews, 19, pp.247-254.

3. Zhang, X. and Mi, C., 2011. Management of Energy Storage Systems in EV, HEV and PHEV. In Vehicle Power Management (pp. 259-286). Springer, London.

4. Vachirasricirikul, S. and Ngamroo, I., 2014. Robust LFC in a smart grid with wind power penetration by coordinated V2G control and frequency controller. IEEE Transactions on Smart Grid,5(1), pp.371-380.

5. Flynn, D., Rather, Z., Ardal, A., D'Arco, S., Hansen, A.D., Cutululis, N.A., Sorensen, P., Estanquiero, A., Gomez, E., Menemenlis, N. and Smith, C., 2017. Technical impacts of high penetration levels of wind power on power system stability. Wiley Interdisciplinary Reviews: Energy and Environment, 6(2), p.e216.

6. Mi, C. and Masrur, M.A., 2017. Hybrid electric vehicles: principles and applications with practical perspectives. John Wiley \& Sons.

7. Delgado, J., Faria, R., Moura, P. and de Almeida, A.T., 2018. Impacts of plug-in electric vehicles in the portuguese electrical grid.Transportation Research Part D: Transport and Environment, 62, pp.372-385.

8. Kabouris, J. and Kanellos, F.D., 2009. Impacts of large scale wind penetration on energy supply industry. Energies, 2(4), pp.10311041.

9. Khodayar, M.E., Wu, L. and Shahidehpour, M., 2012. Hourly Coordination of Electric Vehicle Operation and Volatile Wind Power Generation in SCUC. IEEE Trans. Smart Grid,3(3), pp.1271-1279. 